\title{
Prevalence of Cognitive Distortion and Antisocial Behavior among Bangladeshi Adolescent in Higher Secondary School
}

\author{
Taslima Begum, ${ }^{1,2, *}$ \\ ${ }^{1}$ Department of Psychology, University of Dhaka, Bangladesh \\ ${ }^{2}$ BRAC Institute of Educational Development (BRAC IED), BRAC University, Bangladesh
}

Copyright $\bigcirc 2019$ by authors, all rights reserved. Authors agree that this article remains permanently open access under the terms of the Creative Commons Attribution License 4.0 International License

\begin{abstract}
Over the past 50 years, the rate of antisocial behaviors have increased in frequency and severity among children and adolescent. In a number of studies, cognitive distortions have been shown to be directly related to criminal and antisocial behavior. Hence, it is important to check the frequency of antisocial behavior among adolescent in every society. Thus, the primary aim of this study was to assess the prevalence of cognitive distortion or antisocial behavior among higher secondary adolescent. To determine the cognitive distortion and antisocial behavior the study used the Bangla Version of HIT questionnaire. To measure the prevalence, at first we determine the cutoff score for cognitive distortion and antisocial behavior using ROC curve, sensitivity, specificity and Youden Index. The target sample were 191 higher secondary school going adolescent who are consider as not delinquent or normal sample. Another group of 30 samples was included from juvenile Correction Center considering as delinquent sample to determine the cutoff score. The result found the cutoff score for cognitive distortion or antisocial behavior is 76.5. The result of the study was alarming and found that $42.7 \%$ adolescent were cognitively distorted and had antisocial behavior. The study also found that boys had more antisocial behavior than girls (44.6\% vs $42.7 \%)$. The result also found that socio economic status was related to cognitive distortion and antisocial behavior. These findings suggest that cognitive distortion and antisocial behavior among higher secondary adolescent in Bangladeshi population are public health concern and assumed to threats for society. Since, cognitive distortion of adolescent should be prevented by imposing interventions. In a consequence, we will able to contribute the future national developmental process by reducing crime from Bangladesh.
\end{abstract}

\footnotetext{
Keywords Adolescent, Antisocial Behaviour, Cognitive Distortion, Prevalence, ROC Curve, HIT Questionnaire
}

\section{Introduction}

Presently violence, its consequences and related activities pose a major public health problem for society (Connor, 2002). Researches founded violences are consequences of cognitive distortions, which were found to support the offending behavior (Healy \& O'Donnell, 2006). Cognitive distortions are inaccurate thoughts that are usually used to reinforce negative thinking or emotions-telling ourselves things that sound rational and accurate. In the book, Feeling Good: The New Mood Therapy David Burns (1980) outlined different mistakes in thinking which he called cognitive distortions, are those cognitions which are logical but irrational (Burns \& Bake, 1980). These are simply ways that our mind convinces us of something that is not true. According to Barriga, Landau, Stinson, Liau, and Gibbs (2000), cognitive distortions are inaccurate ways of attending to or conferring meaning on experience. These can be thought as biased processing tendencies and can manifest in internalizing or externalizing manners (Gibbs, Potter, Barriga, \& Liau, 1996). It presents an unrealistic view of reality, which is also maladaptive, because it causes negative mood, impairs behavioral functioning, impedes productive thinking about the situation and reinforces underlying irrational beliefs (Persons, 1989). In a number of studies, cognitive distortions have been shown to be directly related to criminal and antisocial behavior (Andrews, \& Dowden, 1999; Gendreau, Little, \& Goggin, 1996). However, these cognitive distortions may manifest themselves into externalizing problem behaviors such as aggression (Yochelson \& Samenow, 1976). Self-serving cognitive distortions are of particular interest to research as these appear to be related to externalizing behavior problems, particularly delinquent and antisocial behavior (Barriga \& 
Gibbs, 1996; Barriga et al., 2000). Antisocial behaviors are conceptualized as outward behavior that either directly or indirectly harms others through the violation of important moral or social norms, and includes aggressive and delinquent. According to social- cognitive theories, people act upon their interpretation of social events and antisocial behavior is based on deficiencies in interpreting these events, that is, cognitive distortions (Nas et al., 2008). That means self-serving cognitive distortions are those antisocial attitudes that are associated with antisocial behaviors or acts (Barriga et al., 2001). Individuals with a high level of cognitive distortions are likely to exhibit a higher prevalence of antisocial behavior since cognitive distortions can be described as mechanisms of moral disengagement, separating antisocial behavior from self-evaluation (Bandura, 2001), or as mechanisms reducing empathy or guilt (Gibbs, 2003). According to Barriga et al. (2001), self- serving cognitive distortions may be consolidated into a holistic worldview that can be characterized as a 'criminal mind (Cate, 2001). According to Barriga \& Gibbs, 1996; Barriga et al. (2000) antisocial behavior is a kind of cognitive distortion and it can be measured with the same thing such as HITQ (How I Think Questionnaire).

The high prevalence of antisocial behavior among youth is a great societal concern (Redding, Goldstein, \& Heilbrun, 2005), since it forms a substantial risk factor for severe problem behavior, psychopathological disorders, and crime later in life (Moffitt, 2003; Overbeek, Vollebergh, Meeus, Engels, \& Luijpers, 2001). Therefore, the amount of research concerning the development and persistence of antisocial behavior increased substantially during the past decades (Verhulst, 2008). Many theories of antisocial behavior adopted a developmental perspective, which means that origins of antisocial behavior in adulthood are supposed to be found in childhood and adolescence, as the transition from concrete thinking to formal logical operations occurs over time. In this period, each adolescent develops his/her own view of the world. Some adolescents may be able to apply logical operations to school work long before they are able to apply them to personal dilemmas. When emotional issues arise, they often interfere with an adolescent's ability to think in more complex ways. The ability to consider possibilities, as well as facts, may influence decision making, in either positive or negative ways. These abilities to think and reason refer to cognition. Cognition makes us able to judge and reason effectively and make a perception of surrounding that manifest through our behavior. Olugbenga Ojo (2015) posited that antisocial behavior can be identified in children as young as three to four years of age. Furthermore, Crick and Werner (2006) found that antisocial behavior (physical and relational aggression) in elementary school children predicted future social-psychological adjustment problems. In the adolescence period, they are experiencing all kind of new changes in their bodies and in their feelings. As well, they often feel misunderstood as they are struggling to leave behind their childhood and become adult. Adolescence has commonly been characterized by issues such as rebellious behavior, lying, cheating, school performance problems, negative attitudes, disobedience and disrespect, sibling, rivalry, drug and alcohol abuse, pressures from peers, depression, and issues of sexuality.

However, over the past 50 years, the rate of antisocial behaviors has increased in frequency and severity among children and adolescent in the United States (Connor, 2002). Similarly, the number of juvenile delinquents have been increasing in Bangladesh and the rate is alarming for Dhaka city (Nasima, 2011) due to poverty, lack of family support, social transition, migration, broken family, lack of parental attachment with the child, lack of moral education and child trafficking, etc. Moreover, it is the major concern for all over the country (The Daily Observer, 2019). Hence, it is important to check the frequency of antisocial behavior among adolescent in every society, because it can take a serious toll on the country's security along with the person's mental health if left unchecked and untreated cognitive distortion as well as these coercive antisocial behavior patterns. However, the prevalence of antisocial behavior among adolescent is unchecked in Bangladesh. Moreover, there are limited tools that measure cognitive distortion and antisocial behavior (i.e., Bangla version of HIT questionnaire), and the scale lacks cutoff score to identify antisocial adolescent. Thus, the objective of the study was to identify the cutoff score of Bangla HIT questionnaire and to investigate the prevalence of cognitive distortion and antisocial behavior among adolescent in higher secondary school.

\section{Method}

\subsection{Participants}

Two clusters of participants were included in this study. The target sample was higher secondary school going adolescent. These adolescents were considered as normal sample or not delinquent sample. Another group of the delinquent sample was included to determine the cutoff score.

\subsubsection{Delinquent Sample}

To determine the cutoff score, 30 delinquent samples were included in the study. These samples consisted with juvenile delinquents adolescents who were receiving service from the Juvenile Correction Centre, Tongi, Gazipur, Bangladesh. The mean age of these adolescent were $15.5(\mathrm{SD}=.67)$ and age ranges from 15 to 17. According to their perception, around $64 \%$ comes from middle and $32 \%$ comes from low Scio-economic status.

\subsubsection{Not Delinquent or Normal Sample}

A total of 200 adolescents (girls $=94$ ) voluntarily 
participated in this study. They were selected purposively from different colleges in Dhaka, Bangladesh. At first, four colleges were selected conveniently. From each selected college the 11th-grade students attending class were included in the sample. However, because of incomplete responses nine participants (three boys and six girls) were dropped. Among the remaining 191 participants, 88 were girls. The age of these participants ranged from 15 to 18 years, with a mean of 16.61 and a standard deviation of 0.614. Participants' self-reported data indicate that $3.14 \%$ of them came from higher socioeconomic class, $91.62 \%$ from middle socioeconomic class, and 5.24\% from the lower socioeconomic class. The educational qualification of their mothers ranged from below secondary school education to Master's degree $(89.5 \%$ lower education, $8.4 \%$ middle education, $1.0 \%$ higher education, $1.0 \%$ unreported), and that of their fathers ranged from below secondary school education to Ph.D. degree (72.3\% lower education, $21.5 \%$ middle education, $4.7 \%$ higher education, $1.6 \%$ unreported).

\subsection{Measures}

\subsubsection{Bangla Version of How I Think Questionnaire (HIT)}

The HIT was developed to provide a reliable and valid measure of self-serving cognitive distortions in adolescents (Barriaga and Gibbs, 1996; Barriga et al., 2001). The original instrument contains 54 6-point Likert items varying from 'totally agree' (1) to 'totally disagree' (6). Among the 54 items, 39 are clustered in four types of cognitive distortions: Self-centered, Blaming others, Mislabeling/Minimizing, and assuming the worst. Each of the 39 items refers to one of the four antisocial behavioral categories of the DSM-IV (American Psychiatric Association, 1944). These are Oppositional defiance, Physical aggression, Lying, and Stealing. The sum of the 'Oppositional defiance' and the 'Physical aggression' forms the 'Overt' scale, which refers to direct confrontation with the victim in contrast to the 'Covert' scale, which is the sum of the 'Lying' and 'Stealing' categories. Of the remaining 15 items, 8 are 'Anomalous response' items and 7 are 'Positive filler' items designed to camouflage the 39 main distortion items or questions. The original HIT exhibited high test-retest reliability, good internal consistency and construct validity (Barriga and Gibbs, 1996; Barriga et al., 2001). The Bangla version HIT comprises of 27 items under four dimensions which are largely different from the original HIT dimensions (Karim and Begum, 2016). Among 27 items, 10 items measure 'Catastrophizing and mislabeling', 7 items measure 'Emotional reasoning', the items measure 'Self-centeredness and blaming', and 3 items measure 'Overgeneralization'. It does not have any 'Anomalous response' or 'Positive filler' items. However, like the original HIT, the Bangla version HIT also measures four types of antisocial behaviors, and the overt and covert behaviors defined above. The Bangla version HIT and its factors showed acceptable to good internal consistency (Cronbach's a $=0.83$ for the HIT, and 0.40 to 0.77 for its factors), and strong construct validity (Karim and Begum, 2016).

\subsubsection{Data Acquisition}

Standard data collection procedures (Karim and Begum, 2016) were followed in the present study. For delinquent sample at first permission was taken from the Department of Social Welfare and then researcher personally met supervisor- in charge of the Juvenile Correction Center and took consent on behalf of those samples. For the normal sample, the researcher personally met each head/principal of the selected colleges, narrated to him/her the general purpose of the study and got permission to administer the survey on students. On the appointed date and time, the researcher went to a particular college and then to a classroom where she was introduced by the college head/ principal with the 11 th-grade students. Then the general purpose of the study was briefly described to those students, requesting them to cooperate with the researcher. Participants were assured that their responses would be kept confidential and used only for research purposes. After getting their verbal consent the paper-based survey was administered. The survey components included an informed consent statement, socio-demographic section, and the Bangla version HIT (Karim and Begum, 2016). Participants were asked to sign on the consent form, record their socio-demographic information (e.g., gender, age, socio-economic status, parents' educational level), and read carefully the standard instructions of how to respond before going through the items or questions of the scale. The standard instructions included an imperial statement-please do not talk to each other while responding or before finishing the questionnaire. It took over an 8-week period to collect data from all participants.

\subsection{Data Analyses}

Each participant's responses were scored according to the scoring principles of the HIT. Nine participants left a few HIT items with missing responses and were therefore excluded from further processing. Data for the remaining 191 participants were fed into computer for factor analysis on IBM SPSS Statistics 20.

Frequency distribution, percentage and Chi-square tests were used to calculate Prevalence of cognitive distortion and antisocial behavior. Before that, Receiver operating characteristics (ROC) curves were used to determine sensitivity and specificity for each cut-score on the HIT. Presence versus absence of cognitive distortions and antisocial behaviors on the HIT was used as the categorical outcome by comparing delinquent subject with normal adolescent. A ROC curve is a plot of the true positive rate (sensitivity) against the false positive rate (1- specificity) 
for the different possible cut points and thus provides a visual representation of the tradeoff between sensitivity and specificity of cut-scores for a diagnostic test. According to Pepe, Janes, Longton, Leisenring, \& Newcomb (2004), ROC curves are generalization of the set of potential combinations of sensitivity and specificity possible for predictors. Youden index, $\mathrm{j}$ (sensitivity + specificity-1) values were used to calculate percentage of adolescents correctly classified as meeting criteria for cognitive distortion and antisocial behavior based on the most promising cut-scores from the ROC analyses. The sensitivity, specificity, and Youden index, $\mathrm{j}$ values were used to select an appropriate cut-score for identifying adolescents with cognitive distortion and antisocial behaviors using the HIT.

\section{Results}

The goal of present study was to determine prevalence of cognitive distortion and antisocial behavior among Bangladeshi adolescent in Higher Secondary School. For this purpose at first, we determine the cutoff score for cognitive distortion and antisocial behavior. Then at second analysis, prevalence was calculated.

To decide whether HIT total score is good predictor of dichotomous outcome "is/not cognitive distorted", or to decide about trade-off between sensitivity and specificity of HIT total and HIT subscale score cut-off value, we used ROC Curve (Figure 1). Our ROC curve is statistically significant ( $\mathrm{p}=0.00 ; 95 \%$ CI $0.624-0.84)$. Area under the curve is 0.74 (Std. Error=0.05). The point of the curve, which is the closest to the "upper left corner", or has the best balance between sensitivity (0.9) and 1-specificity $(0.4)$, is value of $75 / 76$. Table 1 has also shown that the highest Youden Index, $J$ for HIT total is 0.47 . Hence, the cutoff score for cognitive distortion or antisocial behavior is 76.5 .

ROC for Catastrophizing and mislabeling, subscale of cognitive distortion is statistically significant $(\mathrm{p}=0.00 ; 95 \%$ CI 0.66-0.87). Area under the curve is 0.77 (Std. Error $=0.05$ ) indicates strong validity of Catastrophizing and Mislabeling as a screener. The cut off score with maximum Youden Index is 26.50 for Catastrophizing and Mislabeling (Table 2). The area under the curve for Emotional reasoning is 0.60 , Std. Error $=0.06(\mathrm{p}=0.14 ; 95 \%$ CI 0.47-0.72), according to which we can say that Emotional reasoning score has not use as diagnostic tool. However, the cut off score with maximum Youden Index (.208) is 23.50 for Emotional reasoning (Table 4). For Self-centeredness and blaming subscale, the area under the curve is .650 , Std. Error $=0.05$ which is statistically significant $(\mathrm{p}=0.02 ; 95 \%$ CI $0.55-0.75)$. The cut off score with maximum Youden Index (.34) is 18.50 for Self-centeredness and blaming subscale (Table 3). The cutoff score for Overgeneralization subscale is 11.5 with a maximum Youden index 0.343 (Table 5). The ROC curve for Overgeneralization subscale is significant $(\mathrm{p}=0.00 ; 95 \%$ CI 0.57-0.87). Area under the curve is 0.68 (Std. Error $=0.05$ ). Similarly, Table 6 and figures (6 to 11) represent the area under ROC and cutoff score for corresponding highest Youden Index of antisocial behavior's subscales.

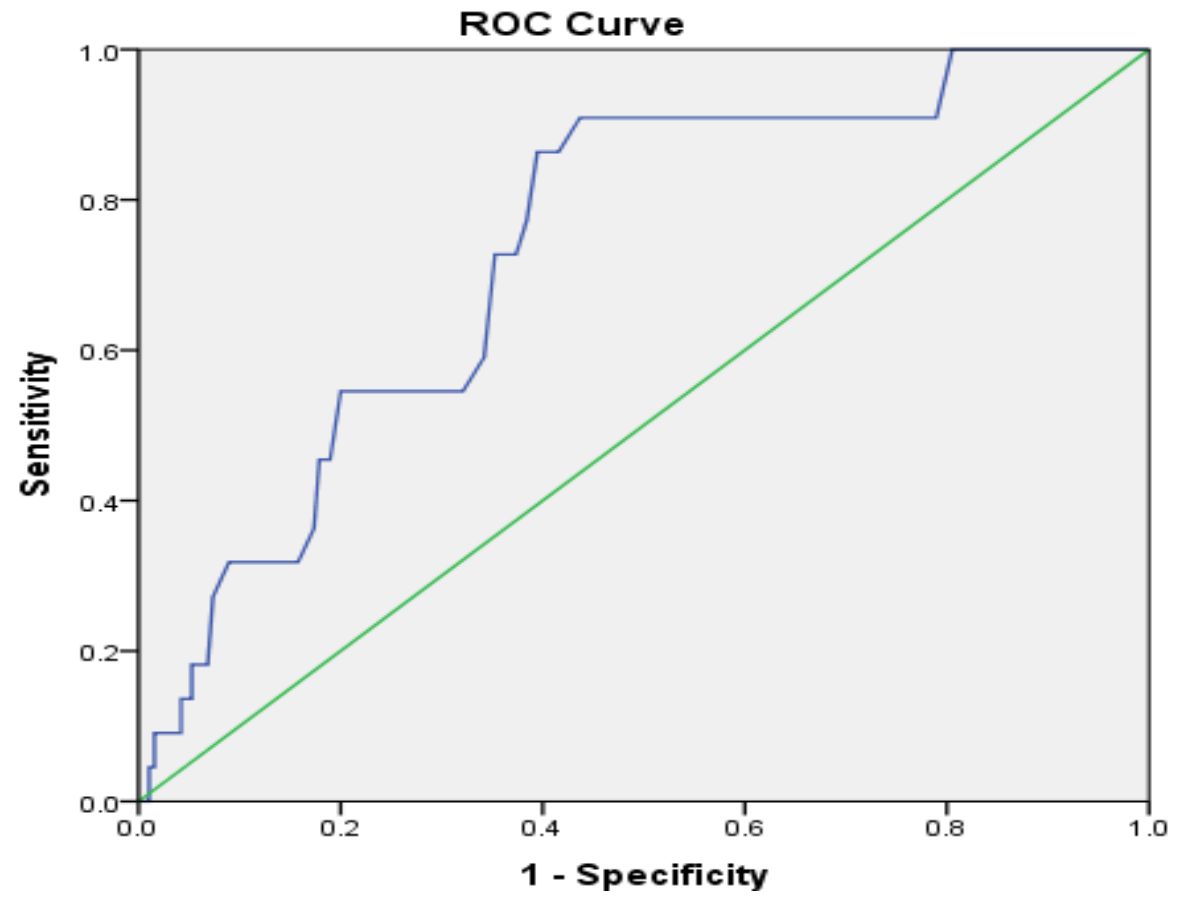

Figure 1. ROC Curve of HIT total score 
Table 1. Criterion values and coordinates of ROC Curve for HIT total score

\begin{tabular}{|c|c|c|c|c|c|c|c|c|c|c|c|}
\hline Criterion & Sensitivity & 1 - Specificity & Youden's index & Criterion & Sensitivity & 1 - Specificity & Youden's index & Criterion & Sensitivity & 1 - Specificity & Youden's index \\
\hline 33.00 & 1.00 & 1.00 & 0.000 & 66.50 & 0.91 & 0.70 & 0.209 & 91.50 & 0.45 & 0.19 & 0.265 \\
\hline 35.50 & 1.00 & 0.99 & 0.005 & 67.50 & 0.91 & 0.67 & 0.241 & 92.50 & 0.45 & 0.18 & 0.276 \\
\hline 37.50 & 1.00 & 0.99 & 0.011 & 68.50 & 0.91 & 0.64 & 0.267 & 93.50 & 0.36 & 0.17 & 0.190 \\
\hline 39.50 & 1.00 & 0.98 & 0.016 & 69.50 & 0.91 & 0.62 & 0.288 & 94.50 & 0.32 & 0.16 & 0.160 \\
\hline 41.50 & 1.00 & 0.98 & 0.021 & 70.50 & 0.91 & 0.59 & 0.320 & 95.50 & 0.32 & 0.15 & 0.171 \\
\hline 42.50 & 1.00 & 0.96 & 0.037 & 71.50 & 0.91 & 0.56 & 0.351 & 96.50 & 0.32 & 0.14 & 0.176 \\
\hline 44.00 & 1.00 & 0.96 & 0.042 & 72.50 & 0.91 & 0.55 & 0.356 & 97.50 & 0.32 & 0.13 & 0.187 \\
\hline 46.00 & 1.00 & 0.95 & 0.047 & 73.50 & 0.91 & 0.53 & 0.378 & 98.50 & 0.32 & 0.12 & 0.197 \\
\hline 47.50 & 1.00 & 0.95 & 0.053 & 74.50 & 0.91 & 0.50 & 0.409 & 99.50 & 0.32 & 0.11 & 0.208 \\
\hline 48.50 & 1.00 & 0.94 & 0.058 & 75.50 & 0.91 & 0.45 & 0.456 & 101.0 & 0.32 & 0.11 & 0.213 \\
\hline 50.00 & 1.00 & 0.94 & 0.063 & 76.50 & 0.91 & 0.44 & 0.472 & 103.0 & 0.32 & 0.09 & 0.229 \\
\hline 51.50 & 1.00 & 0.92 & 0.084 & 77.50 & 0.86 & 0.42 & 0.448 & 104.5 & 0.27 & 0.07 & 0.199 \\
\hline 52.50 & 1.00 & 0.91 & 0.095 & 78.50 & 0.86 & 0.39 & 0.469 & 106.5 & 0.18 & 0.07 & 0.113 \\
\hline 53.50 & 1.00 & 0.90 & 0.100 & 79.50 & 0.77 & 0.38 & 0.389 & 108.5 & 0.18 & 0.05 & 0.129 \\
\hline 54.50 & 1.00 & 0.89 & 0.105 & 80.50 & 0.73 & 0.37 & 0.354 & 109.5 & 0.14 & 0.05 & 0.084 \\
\hline 55.50 & 1.00 & 0.89 & 0.111 & 81.50 & 0.73 & 0.35 & 0.375 & 110.5 & 0.14 & 0.05 & 0.089 \\
\hline 56.50 & 1.00 & 0.86 & 0.137 & 82.50 & 0.59 & 0.34 & 0.249 & 112.0 & 0.14 & 0.04 & 0.094 \\
\hline 58.00 & 1.00 & 0.84 & 0.163 & 83.50 & 0.55 & 0.32 & 0.224 & 114.0 & 0.09 & 0.04 & 0.049 \\
\hline 59.50 & 1.00 & 0.83 & 0.174 & 84.50 & 0.55 & 0.32 & 0.230 & 116.5 & 0.09 & 0.04 & 0.054 \\
\hline 60.50 & 1.00 & 0.81 & 0.189 & 85.50 & 0.55 & 0.29 & 0.256 & 118.5 & 0.09 & 0.03 & 0.065 \\
\hline 61.50 & 1.00 & 0.81 & 0.195 & 86.50 & 0.55 & 0.26 & 0.288 & 121.5 & 0.09 & 0.02 & 0.075 \\
\hline 62.50 & 0.91 & 0.79 & 0.120 & 87.50 & 0.55 & 0.24 & 0.303 & 125.5 & 0.05 & 0.02 & 0.030 \\
\hline 63.50 & 0.91 & 0.76 & 0.146 & 88.50 & 0.55 & 0.21 & 0.335 & 127.5 & 0.05 & 0.01 & 0.035 \\
\hline 64.50 & 0.91 & 0.73 & 0.178 & 89.50 & 0.55 & 0.21 & 0.340 & 128.5 & 0.00 & 0.01 & -0.011 \\
\hline \multirow[t]{2}{*}{65.50} & 0.91 & 0.72 & 0.188 & 90.50 & 0.55 & 0.20 & 0.345 & 134.0 & 0.00 & 0.01 & -0.005 \\
\hline & & & & & & & & 140.0 & 0.00 & 0.00 & 0.000 \\
\hline
\end{tabular}


Table 2. Criterion values and coordinates of ROC Curve for Catastrophizing and mislabeling cognitive distortion

\begin{tabular}{|c|c|c|c|c|c|c|c|c|c|c|c|}
\hline Criterion & Sensitivity & 1 - Specificity & Youden's index & Criterion & Sensitivity & 1 - Specificity & Youden's index & Criterion & Sensitivity & 1 - Specificity & Youden's index \\
\hline 9.00 & 1.00 & 1.00 & 0.00 & 21.50 & 0.82 & 0.41 & 0.41 & 33.50 & 0.41 & 0.09 & 0.32 \\
\hline 10.50 & 1.00 & 0.96 & 0.04 & 22.50 & 0.82 & 0.36 & 0.46 & 34.50 & 0.32 & 0.08 & 0.24 \\
\hline 11.50 & 1.00 & 0.94 & 0.06 & 23.50 & 0.82 & 0.35 & 0.47 & 35.50 & 0.23 & 0.07 & 0.16 \\
\hline 12.50 & 1.00 & 0.91 & 0.09 & 24.50 & 0.82 & 0.35 & 0.47 & 36.50 & 0.18 & 0.06 & 0.12 \\
\hline 13.50 & 1.00 & 0.87 & 0.13 & 25.50 & 0.77 & 0.31 & 0.46 & 37.50 & 0.09 & 0.04 & 0.05 \\
\hline 14.50 & 1.00 & 0.82 & 0.18 & 26.50 & 0.77 & 0.30 & 0.47 & 38.50 & 0.09 & 0.04 & 0.05 \\
\hline 15.50 & 0.91 & 0.77 & 0.13 & 27.50 & 0.73 & 0.28 & 0.44 & 39.50 & 0.09 & 0.03 & 0.06 \\
\hline 16.50 & 0.91 & 0.71 & 0.20 & 28.50 & 0.59 & 0.24 & 0.35 & 40.50 & 0.05 & 0.03 & 0.01 \\
\hline 17.50 & 0.91 & 0.64 & 0.27 & 29.50 & 0.59 & 0.20 & 0.39 & 42.50 & 0.05 & 0.03 & 0.02 \\
\hline 18.50 & 0.82 & 0.57 & 0.25 & 30.50 & 0.59 & 0.16 & 0.43 & 44.50 & 0.05 & 0.02 & 0.02 \\
\hline 19.50 & 0.82 & 0.51 & 0.31 & 31.50 & 0.59 & 0.14 & 0.45 & 46.00 & 0.05 & 0.02 & 0.03 \\
\hline 20.50 & 0.82 & 0.47 & 0.35 & 32.50 & 0.55 & 0.11 & 0.44 & 49.50 & 0.00 & 0.01 & -0.01 \\
\hline & & & & & & & & 53.00 & 0.00 & 0.00 & 0.00 \\
\hline
\end{tabular}

Table 3. Criterion values and coordinates of ROC Curve for Self-centeredness and blaming cognitive distortion

\begin{tabular}{|c|c|c|c|c|c|c|c|c|c|c|c|}
\hline Criterion & Sensitivity & 1 - Specificity & Youden's index & Criterion & Sensitivity & 1 - Specificity & Youden's index & Criterion & Sensitivity & 1 - Specificity & Youden's index \\
\hline 7.00 & 1.00 & 1.00 & 0.00 & 18.50 & 0.86 & 0.52 & 0.34 & 28.50 & 0.18 & 0.13 & 0.05 \\
\hline 8.50 & 1.00 & 0.98 & 0.02 & 19.50 & 0.68 & 0.48 & 0.21 & 29.50 & 0.09 & 0.12 & -0.02 \\
\hline 9.50 & 1.00 & 0.97 & 0.03 & 20.50 & 0.68 & 0.45 & 0.24 & 30.50 & 0.09 & 0.08 & 0.01 \\
\hline 10.50 & 1.00 & 0.94 & 0.06 & 21.50 & 0.59 & 0.40 & 0.19 & 31.50 & 0.09 & 0.05 & 0.04 \\
\hline 11.50 & 1.00 & 0.91 & 0.09 & 22.50 & 0.55 & 0.36 & 0.19 & 32.50 & 0.05 & 0.04 & 0.00 \\
\hline 12.50 & 0.95 & 0.83 & 0.12 & 23.50 & 0.50 & 0.31 & 0.19 & 33.50 & 0.00 & 0.03 & -0.03 \\
\hline 13.50 & 0.95 & 0.77 & 0.18 & 24.50 & 0.32 & 0.27 & 0.05 & 34.50 & 0.00 & 0.03 & -0.03 \\
\hline 14.50 & 0.95 & 0.75 & 0.21 & 25.50 & 0.32 & 0.23 & 0.09 & 36.00 & 0.00 & 0.01 & -0.01 \\
\hline 15.50 & 0.95 & 0.71 & 0.25 & 26.50 & 0.27 & 0.19 & 0.08 & 38.00 & 0.00 & 0.01 \\
\hline 16.50 & 0.91 & 0.64 & 0.27 & 27.50 & 0.18 & 0.16 & 0.02 & 40.00 & 0.00 & 0.00 & -0.01 \\
\hline 17.5000 & .909 & .571 & 0.338 & & & & & & \\
\hline
\end{tabular}


Table 4. Criterion values and coordinates of ROC Curve for Emotional reasoning cognitive distortion

\begin{tabular}{|c|c|c|c|c|c|c|c|c|c|c|c|}
\hline Criterion & Sensitivity & 1 - Specificity & Youden's index & Criterion & Sensitivity & 1 - Specificity & Youden's index & Criterion & Sensitivity & 1 - Specificity & Youden's index \\
\hline 6.00 & 1.00 & 1.00 & 0.00 & 19.50 & 0.82 & 0.72 & 0.10 & 31.50 & 0.14 & 0.12 & 0.02 \\
\hline 7.50 & 1.00 & 0.99 & 0.01 & 20.50 & 0.82 & 0.66 & 0.16 & 32.50 & 0.14 & 0.10 & 0.04 \\
\hline 9.00 & 1.00 & 0.99 & 0.01 & 21.50 & 0.73 & 0.63 & 0.10 & 33.50 & 0.09 & 0.08 & 0.01 \\
\hline 10.50 & 1.00 & 0.98 & 0.02 & 22.50 & 0.68 & 0.53 & 0.16 & 34.50 & 0.09 & 0.06 & 0.03 \\
\hline 11.50 & 0.91 & 0.96 & -0.05 & 23.50 & 0.68 & 0.47 & 0.21 & 36.00 & 0.09 & 0.05 & 0.04 \\
\hline 12.50 & 0.91 & 0.94 & -0.03 & 24.50 & 0.55 & 0.43 & 0.12 & 37.50 & 0.05 & 0.03 & 0.01 \\
\hline 13.50 & 0.91 & 0.93 & -0.02 & 25.50 & 0.45 & 0.32 & 0.14 & 38.50 & 0.05 & 0.02 & 0.02 \\
\hline 14.50 & 0.91 & 0.91 & 0.00 & 26.50 & 0.45 & 0.28 & 0.18 & 39.50 & 0.05 & 0.02 & 0.03 \\
\hline 15.50 & 0.91 & 0.88 & 0.03 & 27.50 & 0.45 & 0.24 & 0.21 & 40.50 & 0.00 & 0.01 & -0.01 \\
\hline 16.50 & 0.91 & 0.84 & 0.07 & 28.50 & 0.36 & 0.21 & 0.15 & 41.50 & 0.00 & 0.01 & -0.01 \\
\hline 17.50 & 0.91 & 0.79 & 0.11 & 29.50 & 0.18 & 0.18 & 0.00 & 43.00 & 0.00 & 0.00 & 0.00 \\
\hline 18.50 & 0.91 & 0.76 & 0.15 & 30.50 & 0.18 & 0.14 & 0.04 & & & & \\
\hline
\end{tabular}


Table 5. Criterion values and coordinates of ROC Curve for Overganalization cognitive distortion

\begin{tabular}{|c|c|c|c|c|c|c|c|}
\hline Criterion & Sensitivity & 1 - Specificity & Youden's index & Criterion & Sensitivity & 1 - Specificity & Youden's index \\
\hline 2.00 & 1.00 & 1.00 & 0.00 & 11.50 & 0.77 & 0.43 & 0.34 \\
\hline 3.50 & 1.00 & 0.98 & 0.02 & 12.50 & 0.59 & 0.35 & 0.25 \\
\hline 4.50 & 0.95 & 0.98 & -0.02 & 13.50 & 0.50 & 0.25 & 0.25 \\
\hline 5.50 & 0.95 & 0.96 & 0.00 & 14.50 & 0.18 & 0.14 & 0.04 \\
\hline 6.50 & 0.95 & 0.90 & 0.05 & 15.50 & 0.18 & 0.11 & 0.07 \\
\hline 7.50 & 0.95 & 0.85 & 0.10 & 16.50 & 0.14 & 0.06 & 0.07 \\
\hline 8.50 & 0.95 & 0.73 & 0.23 & 17.50 & 0.05 & 0.04 & 0.00 \\
\hline 9.50 & 0.86 & 0.64 & 0.22 & 19.00 & 0.00 & 0.00 & 0.00 \\
\hline 10.50 & 0.82 & 0.52 & 0.29 & & & & \\
\hline
\end{tabular}

Table 6. Criterion values for height Youden index, area under ROC for antisocial subscales of HIT

\begin{tabular}{|c|c|c|c|c|c|c|c|}
\hline & \multirow{2}{*}{$\begin{array}{c}\text { Area } \\
\text { under } \\
\text { ROC }\end{array}$} & \multirow{2}{*}{$\begin{array}{l}\text { Std. } \\
\text { Error }\end{array}$} & \multirow{2}{*}{ Asymptotic Sig } & \multicolumn{2}{|c|}{$\begin{array}{c}\text { Asymptotic } 95 \% \\
\text { Confidence Interval }\end{array}$} & \multirow{2}{*}{$\begin{array}{l}\text { Highest } \\
\text { Youden } \\
\text { Index }\end{array}$} & \multirow{2}{*}{$\begin{array}{l}\text { Criterion } \\
\text { value }\end{array}$} \\
\hline & & & & $\begin{array}{l}\text { Lower } \\
\text { Bound }\end{array}$ & $\begin{array}{l}\text { Upper } \\
\text { Bound }\end{array}$ & & \\
\hline Lying & 0.65 & 0.06 & 0.02 & 0.53 & 0.76 & 0.28 & 25.50 \\
\hline Stealing & 0.78 & 0.04 & 0.00 & 0.70 & 0.87 & 0.54 & 20.50 \\
\hline Oppositional defiance & 0.73 & 0.05 & 0.00 & 0.64 & 0.82 & 0.37 & 14.50 \\
\hline Physical aggression & 0.71 & 0.06 & 0.00 & 0.60 & 0.82 & 0.48 & 16.50 \\
\hline Covert Behavior & 0.75 & 0.05 & 0.00 & 0.65 & 0.84 & 0.40 & 40.50 \\
\hline Overt behavior & 0.75 & 0.05 & 0.00 & 0.66 & 0.84 & 0.48 & 33.50 \\
\hline
\end{tabular}

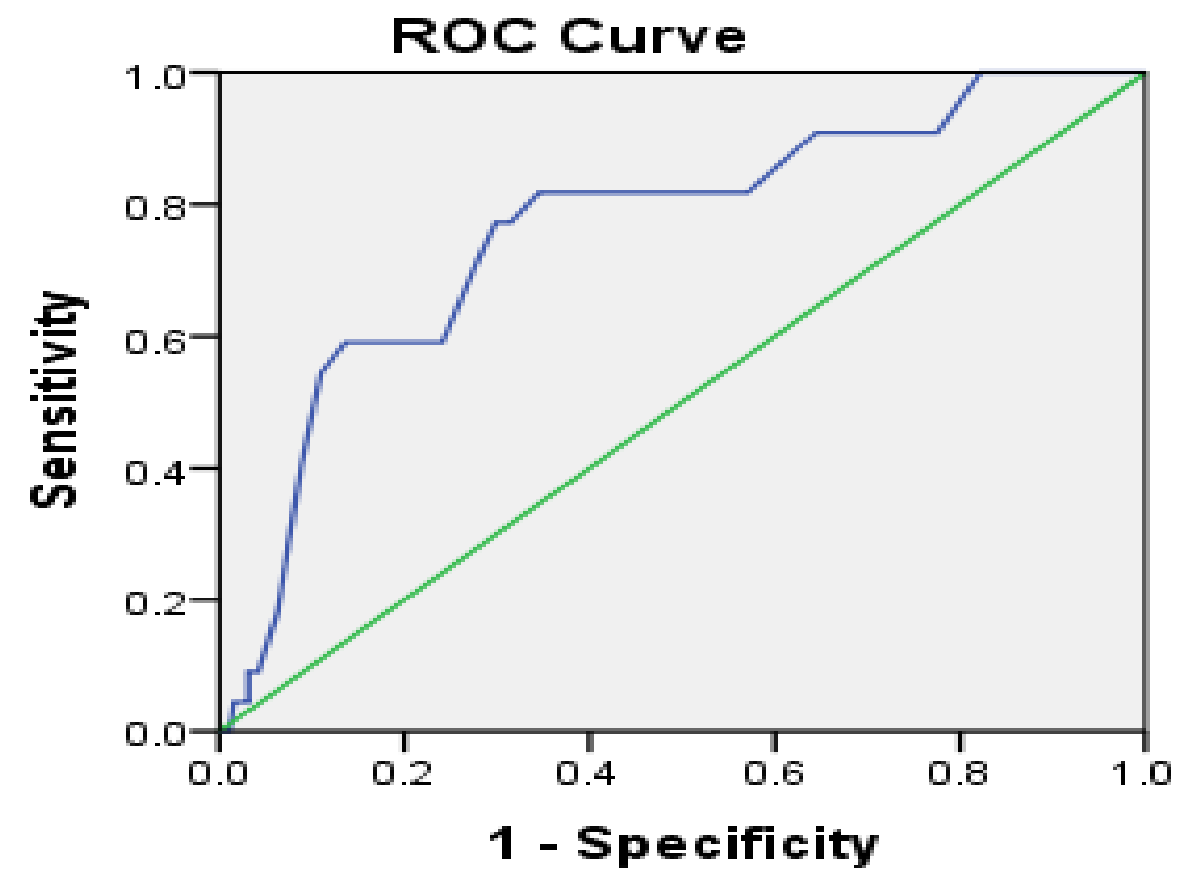

Figure 2. ROC curve of Catastrophizing and Mislabeling subscale 


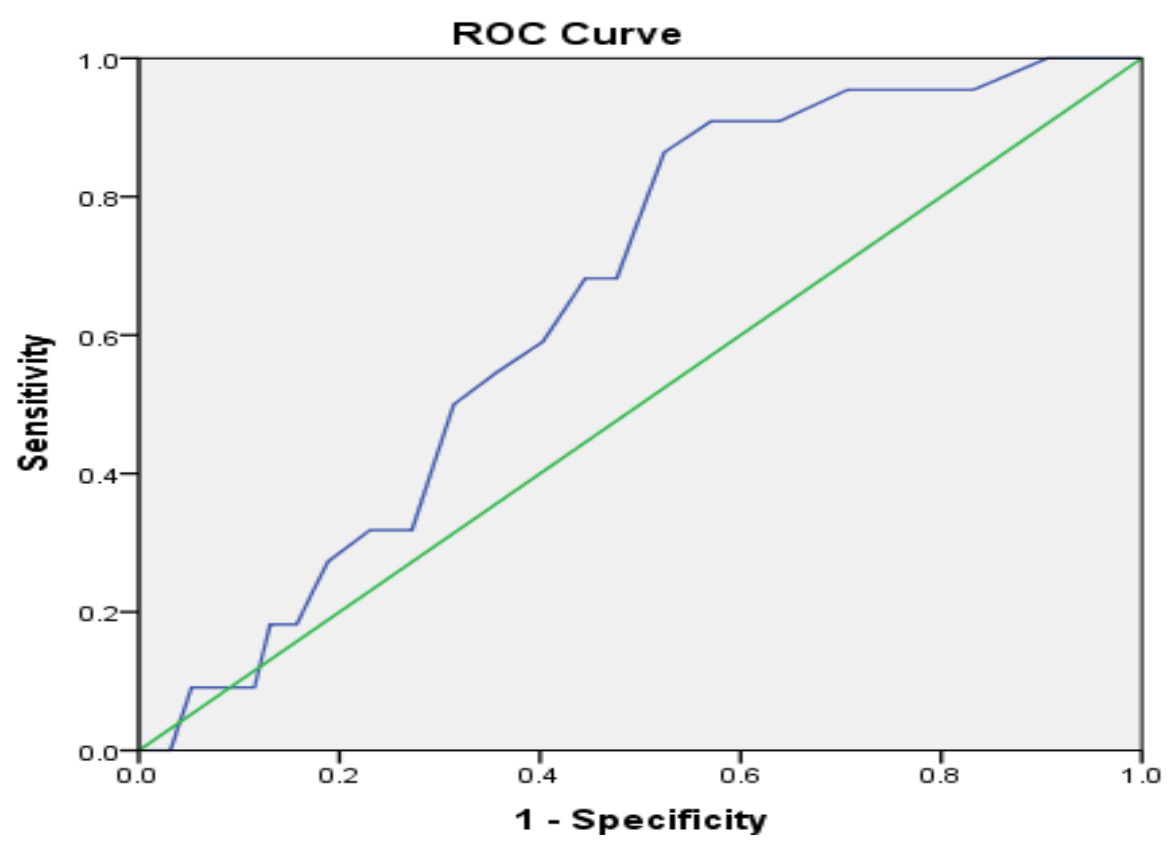

Figure 3. ROC curve of Self-centeredness and blaming subscale

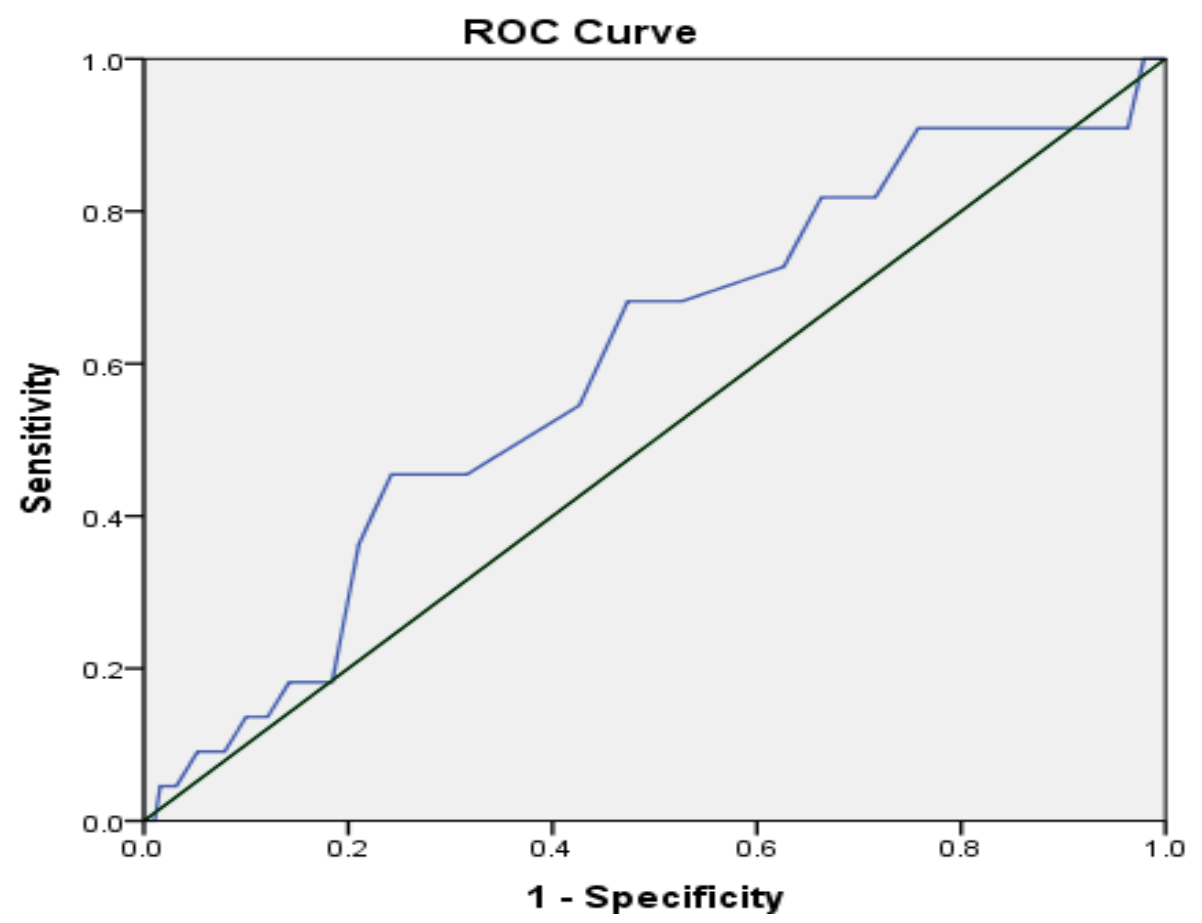

Figure 4. ROC curve of Emotional Reasoning subscale 


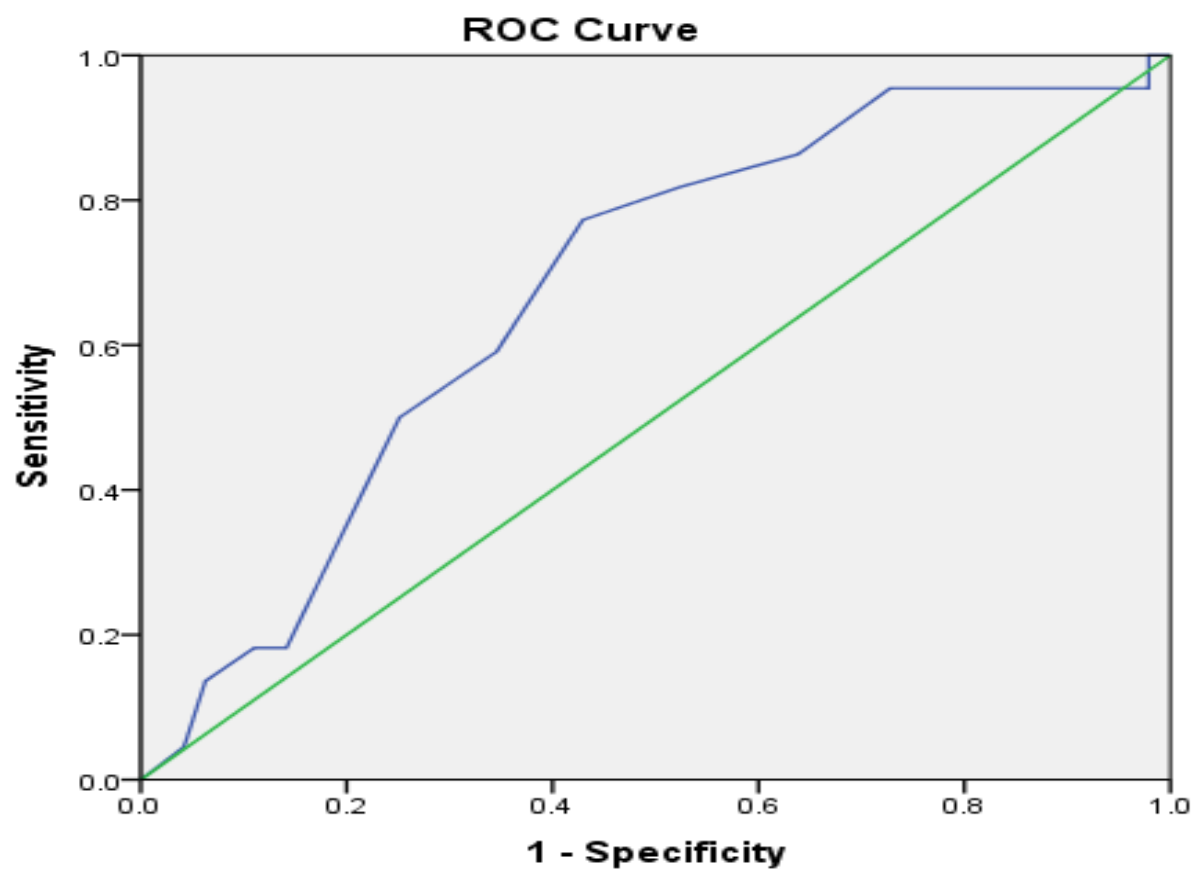

Figure 5. ROC curve of Overgeneralization subscale

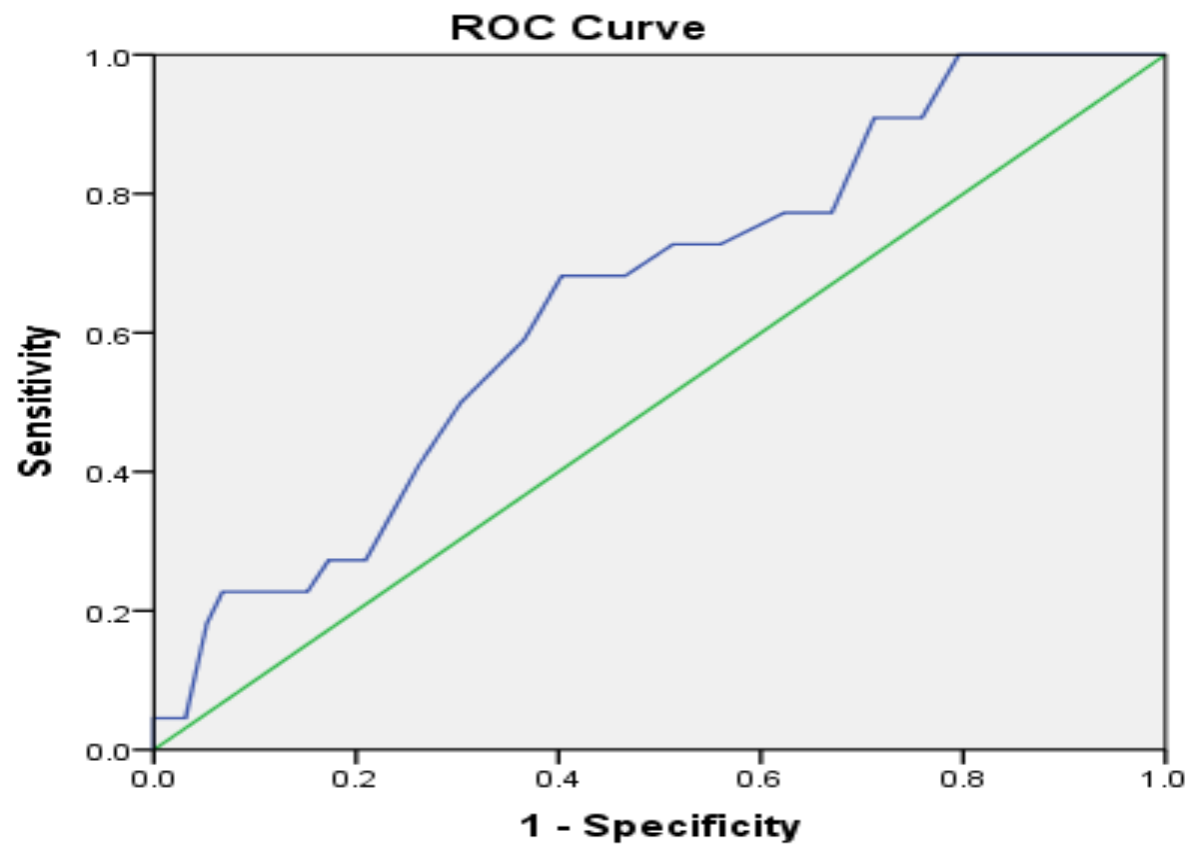

Figure 6. ROC curve of Lying antisocial subscale 


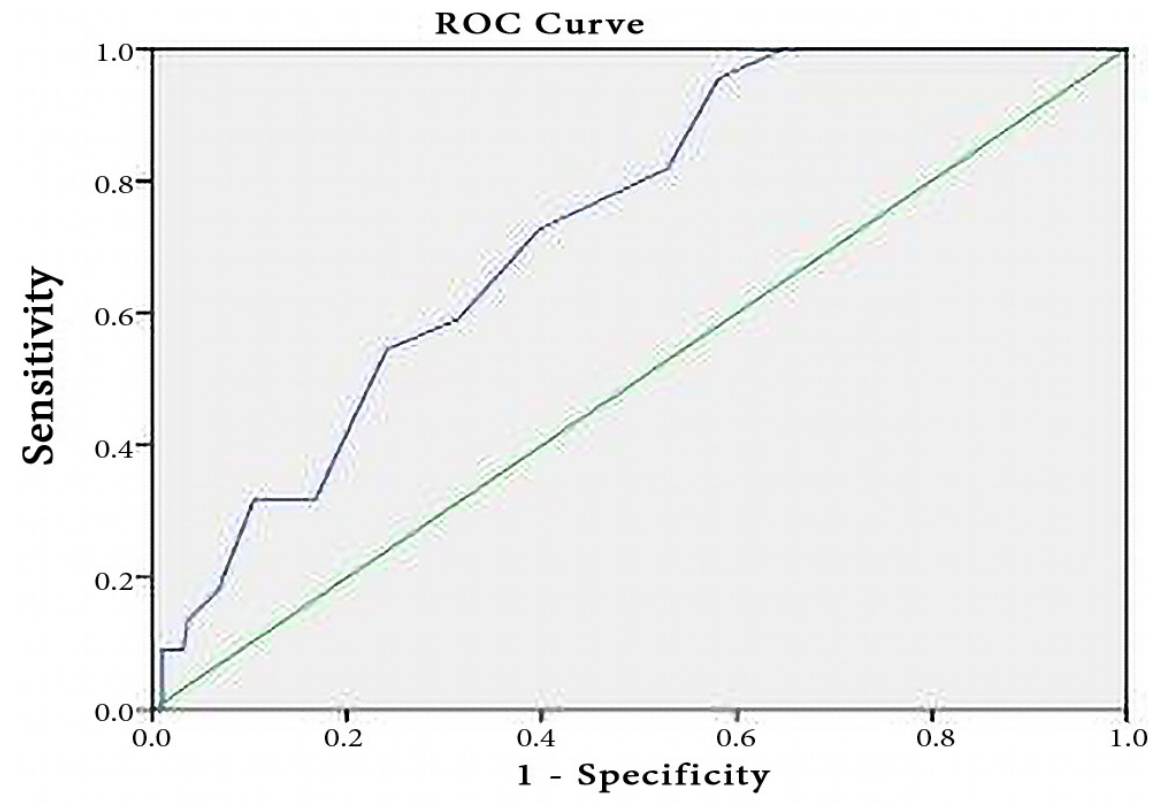

Figure 7. ROC curve of Oppositional Defiance subscale

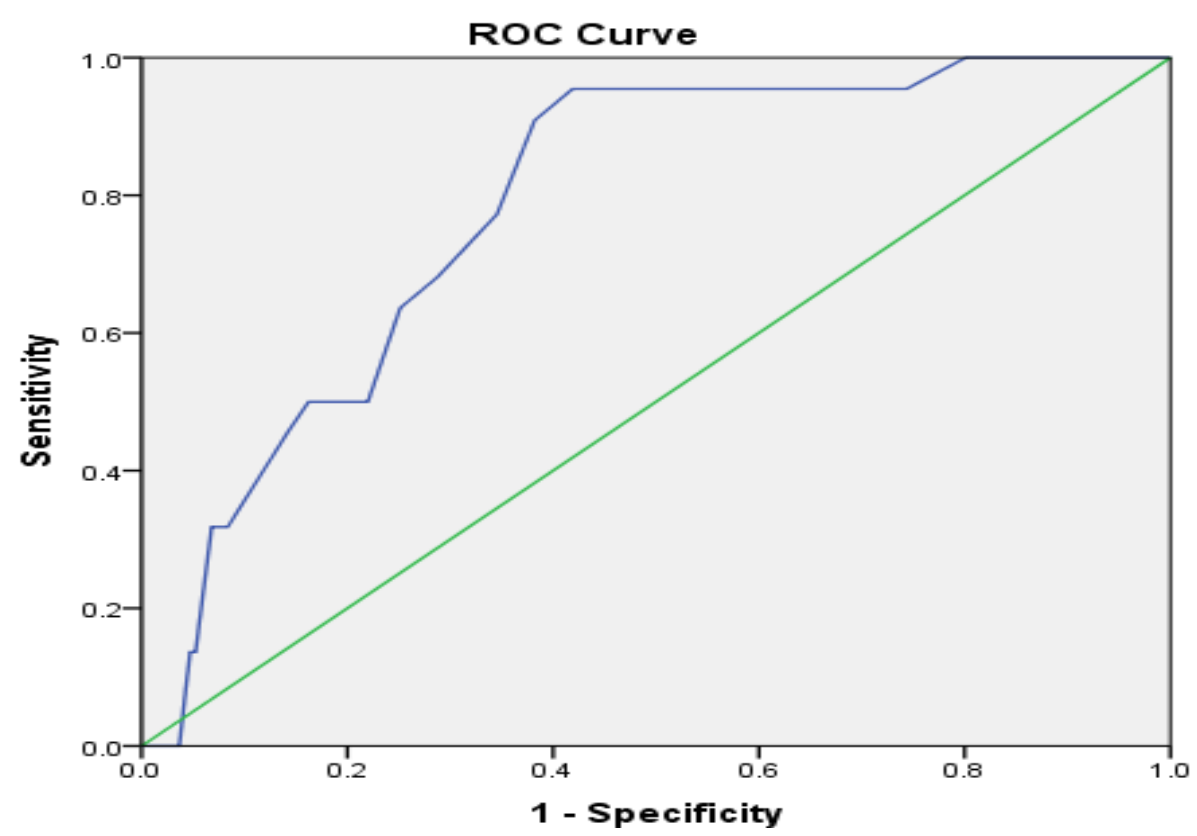

Figure 8. ROC curve of Stealing antisocial behavior 


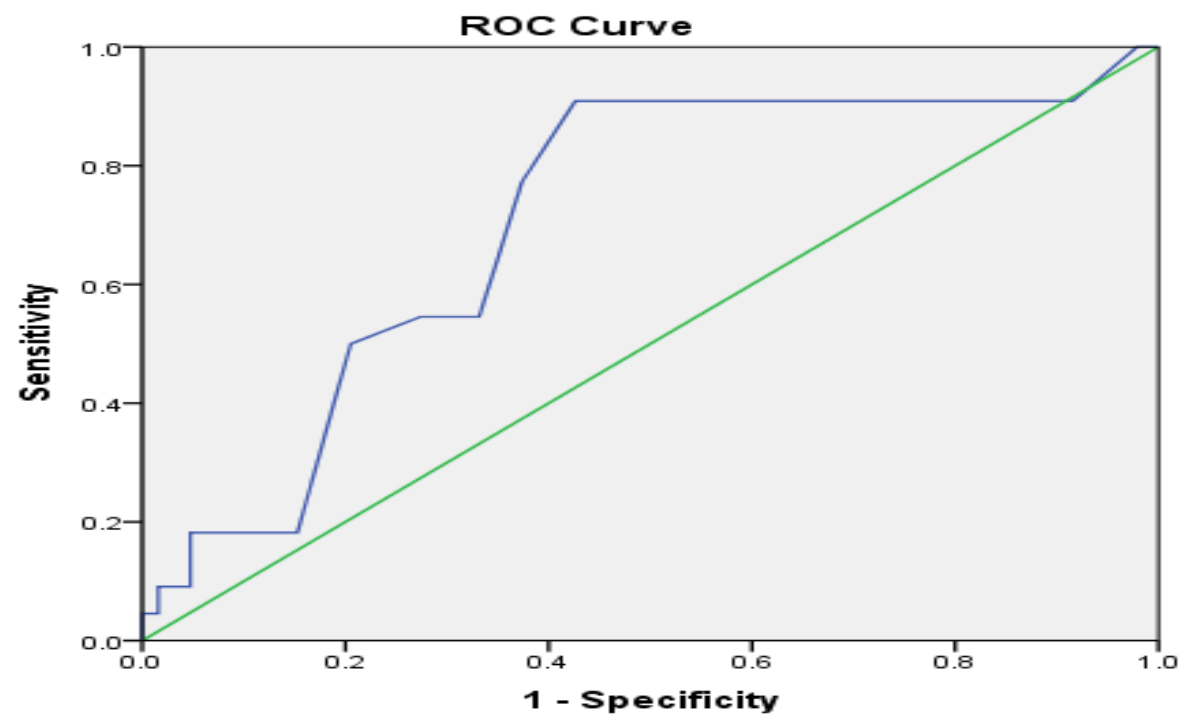

Diagonal segments are produced by ties.

Figure 9. ROC curve of Physical aggression antisocial behavior

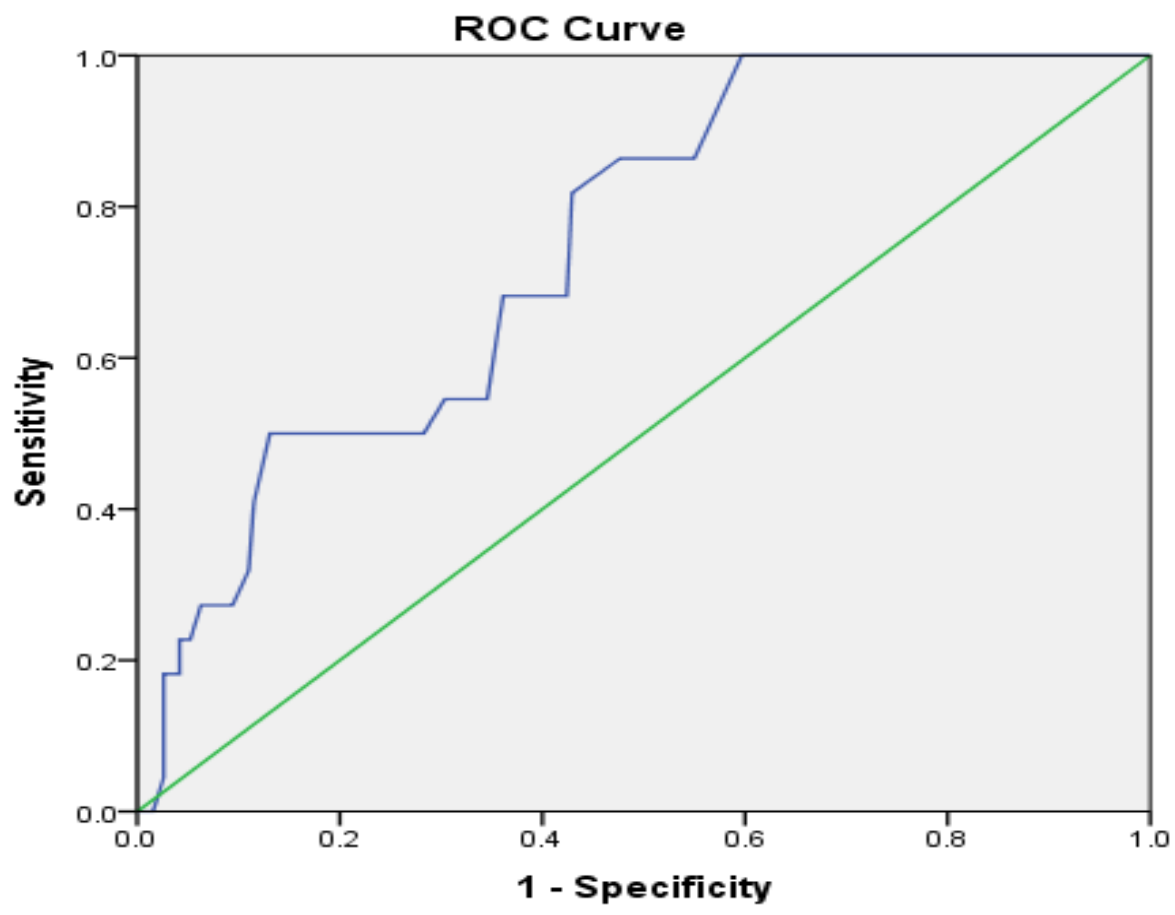

Figure 10. ROC of curve of Covert antisocial behavior 


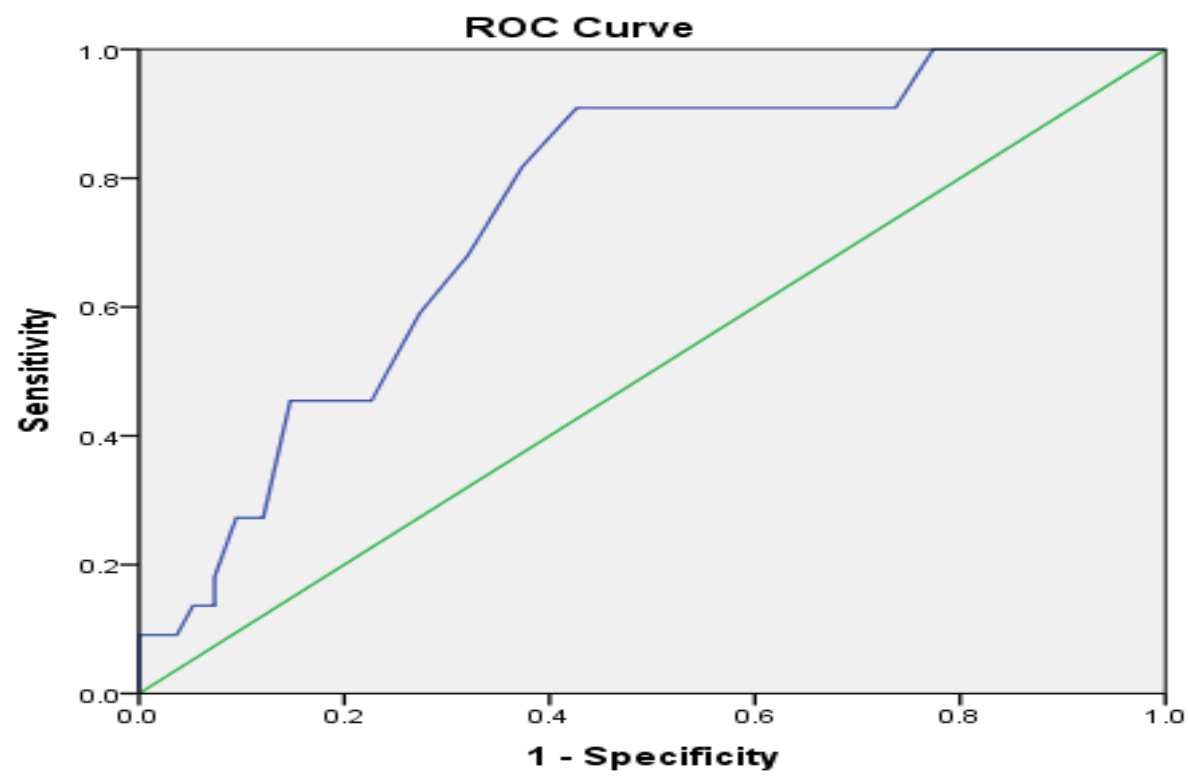

Figure 11. ROC curve of Overt antisocial behavior

\section{Prevalence of Cognitive Distortion and Antisocial Behavior}

Among 191 participants, $53.4 \%$ were boys and $46.6 \%$ were girls. The mean age of participants was 16.5 years $(16.33$ for girls and 16.66 for boys). Table 7 shows the selected characteristics of the study subjects. The majority of the participants' were from middle socio economic status according to their perception.

Table 7. Selected socio-demographic characteristics of the sample populations

\begin{tabular}{|c|c|c|c|}
\hline Characteristics & Girl & Boy & Total \\
\hline & $\mathrm{n}=89$ & $\mathrm{n}=102$ & $\mathrm{n}=191$ \\
\hline Number of sibling & $3(1-10)$ & $3(1-8)$ & $3(1-10)$ \\
\hline Birth order & $2(1-9)$ & $2(1-8)$ & $2(1-9)$ \\
\hline Nuclear family & $80 \%$ & $84.3 \%$ & $83.2 \%$ \\
\hline GPA in SSC & $3.96 \pm 0.63$ & $4.67 \pm 0.49$ & $4.33 \pm .66$ \\
\hline \multicolumn{4}{|c|}{ Fathers' occupation } \\
\hline teacher & $3.4 \%$ & $15.7 \%$ & $9.9 \%$ \\
\hline services holder & $31.5 \%$ & $28.4 \%$ & $29.8 \%$ \\
\hline Business & $61.8 \%$ & $40.2 \%$ & $50.3 \%$ \\
\hline labor/driver/home servant & $1.1 \%$ & $4.9 \%$ & $3.1 \%$ \\
\hline farmer & $0.0 \%$ & $8.8 \%$ & $4.7 \%$ \\
\hline \multicolumn{4}{|c|}{ Mothers' occupation } \\
\hline home maker & $92.1 \%$ & $89.2 \%$ & $90.6 \%$ \\
\hline teacher & $1.1 \%$ & $9.8 \%$ & $5.8 \%$ \\
\hline service holder & $5.6 \%$ & $1.0 \%$ & $3.1 \%$ \\
\hline Business & $1.1 \%$ & $0.0 \%$ & $.5 \%$ \\
\hline \multicolumn{4}{|c|}{ Fathers' education } \\
\hline below SSC & $19.1 \%$ & $16.7 \%$ & $17.8 \%$ \\
\hline $\mathrm{SSC}$ & $30.3 \%$ & $35.3 \%$ & $33.0 \%$ \\
\hline HSC & $23.6 \%$ & $19.6 \%$ & $21.5 \%$ \\
\hline Degree/ Honors & $21.3 \%$ & $21.6 \%$ & $21.5 \%$ \\
\hline MA/Masters & $3.4 \%$ & $3.9 \%$ & $3.7 \%$ \\
\hline \multicolumn{4}{|c|}{ Mothers education } \\
\hline
\end{tabular}




\begin{tabular}{|c|c|c|c|}
\hline below SSC & $28.1 \%$ & $28.4 \%$ & $28.3 \%$ \\
\hline SSC & $47.2 \%$ & $43.1 \%$ & $45.0 \%$ \\
\hline HSC & $15.7 \%$ & $16.7 \%$ & $16.2 \%$ \\
\hline degree/ Honors & $6.7 \%$ & $9.8 \%$ & $8.4 \%$ \\
\hline MA/ Masters & $1.1 \%$ & $1.0 \%$ & $1.0 \%$ \\
\hline \multicolumn{2}{|c|}{ Monthly family income } \\
\hline$<25000$ & $43.8 \%$ & $63.7 \%$ & $54.5 \%$ \\
\hline$<50000$ & $19.1 \%$ & $19.6 \%$ & $19.4 \%$ \\
\hline$\geq 50000$ & $37.1 \%$ & $16.7 \%$ & $26.2 \%$ \\
\hline
\end{tabular}

The prevalence of cognitive distortion/ antisocial behavior was $42.7 \%$ and the prevalence in boys and girls were $44.6 \%$ and $42.7 \%$ respectively. The prevalence of different cognitive distortion and antisocial dimensions are presented in table 8 . From the table, it has shown that prevalence of cognitive distortions and antisocial behaviors were high among study population. Catastrophizing and mislabeling, and Emotional reasoning are higher among boys adolescent. Similarly, overt antisocial behavior is higher among boys.

Table 8. The prevalence of cognitive distortions and antisocial behaviors by sex

\begin{tabular}{|c|c|c|c|}
\hline Subscale/ dimension & Girl & Boy & Total \\
\hline \multicolumn{4}{|l|}{ Cognitive distortion } \\
\hline Catastrophizing and mislabeling & $24.72 \%$ & $41.94 \%$ & $34.74 \%$ \\
\hline Emotional reasoning & 39.33 & 56.45 & 49.30 \\
\hline Self-centeredness and blaming & $57.3 \%$ & $54.8 \%$ & $55.9 \%$ \\
\hline Overgeneralization & $56.2 \%$ & $54.8 \%$ & $55.4 \%$ \\
\hline \multicolumn{4}{|l|}{ Antisocial behavior } \\
\hline Lying & $42.7 \%$ & $43.5 \%$ & $43.2 \%$ \\
\hline Stealing & $44.9 \%$ & $49.2 \%$ & $47.4 \%$ \\
\hline Oppositional defiance & $57.3 \%$ & $69.9 \%$ & $64.6 \%$ \\
\hline Physical aggression & $42.7 \%$ & $43.5 \%$ & $43.2 \%$ \\
\hline Covert Behavior & $60.7 \%$ & $66.1 \%$ & $63.8 \%$ \\
\hline Overt behavior & $39.3 \%$ & $53.7 \%$ & $47.6 \%$ \\
\hline
\end{tabular}

From figure 12, it has been shown that adolescent belong to richer family have more cognitive distortion or antisocial behavior. Group differences have done by $\mathrm{X}^{2}$ test. Income more than $50000\left(\mathrm{X}^{2}=172.38, p=.03\right)$ and businessman fathers' children $\left(\mathrm{X}^{2}=1594.1172 .38, p=.00\right)$ were significantly higher cognitive distortion.

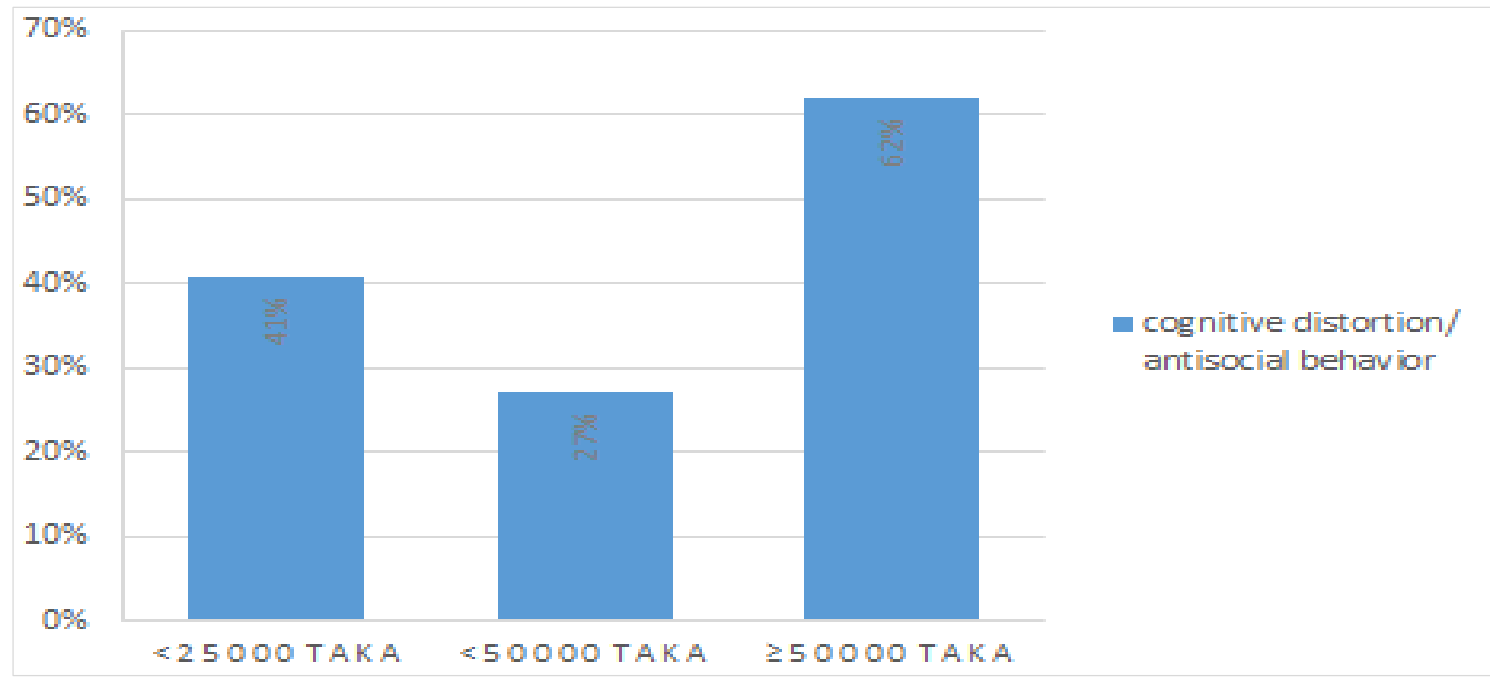

Figure 12. Percentage of participants' total cognitive distortion or antisocial behavior by monthly family income 
Table 9 has shown the differences between mean \pm SD and their $\mathrm{P}$ values between girls and boys for dimensions of cognitive distortion and antisocial behavior. The mean physical aggression antisocial behavior was significantly higher $(p<0.01)$ for boys than girls. Bivariate correlation revealed that participants' obtained GPA at SSC examination negatively correlated with covert antisocial behavior $(\mathrm{r}=-.149, \mathrm{p}<.05)$ and mothers' educational attainment negatively correlated with self-centeredness and blaming cognitive distortion $(\mathrm{r}=-.185, \mathrm{p}<.05)$ and stealing antisocial behavior $(\mathrm{r}=-.171, \mathrm{p}<.05)$, indicating lower the mothers' education higher the self-centeredness and blaming, and stealing behavior of adolescents. However, fathers education were not associated with children's cognitive distortion or antisocial behavior.

Table 9. The mean cognitive distortion and antisocial behavior by sex

\begin{tabular}{|c|c|c|c|}
\hline \multirow{2}{*}{ Variable } & Boy & Girl & \multirow{2}{*}{ P value } \\
\cline { 2 - 3 } & Mean \pm SD & Mean \pm SD & \\
\hline $\begin{array}{c}\text { Catastrophizing and } \\
\text { mislabeling }\end{array}$ & $22.7 \pm 8.8$ & $21.2 \pm 8.1$ & 0.25 \\
\hline Emotional reasoning & $23.8 \pm 7.0$ & $22.8 \pm 6.6$ & 0.33 \\
\hline $\begin{array}{c}\text { Self centeredness and } \\
\text { blaming }\end{array}$ & $19.1 \pm 6.5$ & $20.9 \pm 7.3$ & 0.08 \\
\hline overgeneralization & $10.8 \pm 3.3$ & $11.1 \pm 3.7$ & 0.64 \\
\hline lying & $24.0 \pm 7.2$ & $24.1 \pm 7.1$ & 0.88 \\
\hline Stealing & $19.3 \pm 6.6$ & $20.2 \pm 6.3$ & 0.32 \\
\hline Physiacal agression & $17.3 \pm 5.6$ & $15.5 \pm 4.8$ & 0.01 \\
\hline Oppsitional definances & $15.3 \pm 4.2$ & $15.7 \pm 5.1$ & 0.49 \\
\hline Covert & $43.2 \pm 11.8$ & $44.3 \pm 11.4$ & 0.51 \\
\hline Overt & $32.6 \pm 8.8$ & $31.2 \pm 8.7$ & 0.28 \\
\hline $\begin{array}{c}\text { Total (Cognitive distortion/ } \\
\text { antisocial behavior) }\end{array}$ & $76.3 \pm 19.2$ & $76.0 \pm 18.7$ & 0.91 \\
\hline
\end{tabular}

\section{Discussion}

Cognitively distorted individual assume their irrational thoughts are rational and more likely to violate norms, since cognitions expresses through behavior. Norms are typically defined as prescribed behaviors or attitudes that are considered acceptable or desirable in a given society. In Bangladesh, stealing, teasing, group violence and sex offence are common form of antisocial behavior for adolescent (Hasan, 2018). Thus the study used Bangla HIT questionnaire to measure cognitive distortion and antisocial behavior as HIT was widely used to measure cognitive distortion and antisocial behavior. The primary aim of this study was to identify the cutoff score of Bangla HIT questionnaire, which measures cognitive distortion and antisocial behavior (Karim \& Begum, 2016), and to assess the prevalence of cognitive distortion or antisocial behavior among Bangladeshi higher secondary adolescent.

To measure the prevalence, at first we determine the cutoff score for cognitive distortion and antisocial behavior using ROC curve and Youden Index. However, Krzanowski and Hand (2009) recommended the highest Youden Index $(J)$ to find the cutoff score. Ruopp, Perkins, Whitcomb, \& Schisterman (2008) have defined Youden Index (Youden Index, $J=$ Sensitivity + Specificity -1 ), the maximum potential effectiveness of a biomarker, is a common summary measure of the ROC curve. The area under the curve is 0.74 (Std. Error $=0.05$ ) for HIT, according to which we can say that HIT total score has some use as a diagnostic tool (Zweig, M.H. and Campbell, G., 1993). Areas under the curve for Cognitive distortion subscales except Emotional reasoning indicate strong validity of as a screener. Similarly, all the areas (figure 6-11) indicate strong validity and all cutoff score significantly measure antisocial behaviors.

The result of the study was alarming and found that $42.7 \%$ adolescent were cognitively distorted and had antisocial behavior. The study also found that boys had more antisocial behavior than girls $(44.6 \%$ vs $42.7 \%)$, which was similar to Connor (2002) for American population. Consistently, Siddique (2015) cited juvenile delinquency is the rapidly growing problem in Bangladesh. Reason behind the rapid growth of antisocial behavior might be for negative aspect of rapid globalization such as abuse of internet, terrorism, broken family, lack of parents-child attachment. Moreover, poverty, lack of moral education might be possible cause for rapid growth of crime. The study found that boy meet more antisocial behavior than girls' might be for parents used different parenting style for raise up their boys and girls children for safety and security reason. The study also found that boys have more Catastrophizing and mislabeling, Emotional reasoning types of cognitive distortion and overt antisocial behaviors. Similarly, the mean physical aggression antisocial behavior was significantly higher $(p<0.01)$ for boys than the girls. Consistently; Velden, Brugman, Boom, and Willem (2008) found a difference in cognitive distortions between boys and girls, with more cognitive distortions for boys. The result also found that adolescent comes from higher monthly family income had higher cognitive distortion or antisocial behavior possible for parents form these families to spend more time for income generation and give less time to their children. Moreover, fathers and mothers education were correlated with adolescents' self-centeredness and blaming and stealing behavior. This might because of parents with lower educational qualification failed to teach right values for their children. This study indicates a negative correlation between covert antisocial behavior (stealing and laying) and respondents' academic achievement (obtained GPA at SSC level). This might do for avoiding punishments. Parents of adolescent with poor academic performance often scold and punish their children. In a result, these adolescents tell lie.

Taken as a whole, these findings suggest that cognitive distortion and antisocial behavior among higher secondary 
adolescent in the Bangladeshi population are a public health concern and assumed threats for society. Since prevention is better than remedy, cognitive distortion of adolescents should be prevented by imposing interventions. In a consequence, the study will able to contribute to the future national developmental process by reducing crime from Bangladesh.

\section{Limitations}

Although the present study tried to maintain a sound methodology and analysis of data, nerveless it is not free from certain drawbacks and limitations. Following may be said to be the major limitations of the study, the number of respondent was small especially delinquent subject used for determining cutoff score were very small. Due to shortage of time and lack of financial and other support, data were collected only from Dhaka city. Thus, it cannot be claimed that the sample was representative. The study could not control some of the extraneous variable like socioeconomic condition, number of siblings and others which could affect the result of the study.

\section{Recommendations}

The following recommendations are made in curbing the incidence of antisocial behaviors and cognitive distortion among higher secondary school adolescent

(1) There should be counsellors in our schools, in order to assist students who exhibit antisocial behaviors or those at risk, so that they can live normal life.

(2) There should be early detection of repeated lying, cheating, stealing, aggression, self-centeredness and blaming, emotional reasoning, catastrophizing and other cognitive distortions in adolescent, so that such behaviors will not lead to antisocial behaviors or criminal behavior later in life.

(3) Further research should be conducted to investigate the causes of these cognitive distortion and antisocial behaviors.

(4) The students with cognitive distortion should be engaged in extracurricular activities like literary and debating club, scout, sports where leadership abilities are being encouraged. This will enable them to spend their time on meaningful activities, rather than antisocial behaviors.

\section{REFERENCES}

[1] Ainsworth, M.D.S., Blehar, M.C., Waters, E., Wall. S. (1978). Patterns of attachment: a psychological study of the Strange Situation. Hillsdale, NJ, USA: Erlbaum.
[2] American Psychiatric Association. (1994). Diagnostic and Statistical Manual of Mental Disorders (4th ed.). Washington, DC: Author of juvenile delinquents: A meta-analysis. Journal of Abnormal Child Psychology, 34, 697-713.

[3] Bandura, A. (2001). Social-cognitive theory of moral thought and action. Hillsdale, NJ: Erlbaum.

[4] Barriga, A.Q. \& Gibbs, J.C. (1996). Measuring cognitive distortion in antisocial youth: development of the "How I Think" Questionnaire, Aggressive Behavior, 22, 333-343.

[5] Barriga, A.Q., Gibbs, J.C., Potter, G.B., \& Liau, A.K. (2001). How I Think (HIT) Questionnaire manual, Champaign, IL: Research Press.

[6] Barriga, A. Q., Hawkins, M. A., \& Camelia, C. R. (2008) Specificity of cognitive distortions to antisocial behaviors, Criminal Behavior and Mental Health, 18, 104-116.

[7] Barriga, A. Q., Landau, J. R., Stinson, B.L. II, Liau, A.K., \& Gibbs, J.C. (2000). Cognitive distortion and problem behaviors in adolescents, Criminal Justice and Behavior, 27, 36-56.

[8] Burns, D. D. (1980). Feeing good: The new mood therapy. New York, William Morrow.

[9] Cate, A., T. (2001). Cognitive distortions as predictor of antisocial behavior in children (Un published master's thesis). Thesis collection for Utrecht University, Netherlands.

[10] Connor, D. (2002). Prevalence of aggression, antisocial behaviors, and suicide. Aggression and Antisocial Behavior in Children and Adolescensts: Research and Treatment, 28-45.

[11] Crick, N.R., Ostrov, J.M., \& Werner, N.E. (2006). A longitudinal study of relational aggression, physical aggression, and children's social- psychological adjustment. Journal of Abnormal Child Psychology, 34 (2), 131- 142.

[12] Deirdre, H., \& Donnell, O. (2006). Criminal Thinking on Probation: A Perspective from Ireland. Criminal Justice and Behavior, 23-29.

[13] Gibbs, J. C. (2003). Moral development and reality. Beyond the Theories of Kohlberg and Hoffman. Thousand Oaks, CA: Sage.

[14] Hasan, S. (2018). Juvenile delinquency in Bangladesh. The Independent, 10 November, 2018.

[15] Karim, A.K.M.R. \& Begum, T. (2016). The How I Think questionnaire: Assessing its psychometric properties in Bangladeshi culture. Asian Journal of Psychiatry, 21, 9-16.

[16] Krzanowski, W. J. \&. Hand, D. J (2009). A Review of: "ROC Curves for Continuous Data. Journal of Biopharmaceutical Statistics, 20 (Issue 2: Statistical Genomics in Clinical Trials), 485-87.

[17] Moffitt, T. E. (2003). Life-course-persistent and adolescence-limited antisocial behavior: A 10-year research review and a research agenda. In B. B. Lahey, T. E. Moffitt, \& A. Caspi (Eds.), Causes of conduct disorder and juvenile delinquency (pp. 49-75). New York, NY, US: Guilford Press. 
[18] Nas, C. N., Brugman, D., \& Koops, W. (2008). Measuring Self-Serving Cognitive Distortions with the "How I Think" Questionnaire, European Journal of Psychological, 24(3), 181-189.

[19] Olugbenga Ojo, I. (2015). Causes and Prevalence of Antisocial Behaviour among Students with Hearing Impairment in Ibadan, Nigeria. Journal of Education and Practice, 6(28), 38-43. Retrieved from https://files.eric.ed. gov/fulltext/EJ1081200.

[20] Overbeek, G., Vollebergh, W., Meeus, W., Engels, R., \& Luijpers, E. (2001). Course, co-occurrence, and longitudinal associations of emotionan disturbance and delinquency from adolescence to young adulthood: A six-year three-wave study. Journal of Youth and Adolescence, 30(4), 401-426.

[21] Parvin, Nasima (2011). Juvenile delinquency and juvenile justice system in Bangladesh, Unpublished manuscript, Dhaka.

[22] Peasons, B. (1989). Cognitive Therapy in Practice: A case formatting approach. Boston, Mc Grage Hill.

[23] Pepe, M.S., Janes, H., Longton, G., Leisenring, W., \& Newcomb, P. (204). Limitations of the odds ratio in gauging the performance of a diagnostic, prognostic, or screening marker. Am J Epidemiol, 159 (9), 882-90.

[24] Ruopp, M. D., Perkins, N. J., Whitcomb, B. W., \& Schisterman, E. F. (2008). Youden Index and optimal cut-point estimated from observations affected by a lower limit of detection. Biometrical Journal. https://doi.org/10.1 002/bimj.200710415.

[25] Md. Kaoser Bin Siddique, K., B., Hossain, F., Kashemi, F., Islam, R., \& Mirdha, T., A. (2015). Juvenile Delinquency: A Study on the Juvenile Development Centre, Tongi, Gazipur, Bangladesh.

[26] Majbahin, P (2017). Juvenile delinquency in Bangladesh: Causes and consequences. The daily observer, 14 September, Dhaka.

[27] van der Velden, F., Brugman, D., Boom, J., \& Koops, W. (2010). Effects of EQUIP for educators on students' self-serving cognitive distortions, moral judgment, and antisocial behavior. Journal of Research in Character Education, 8 (1), 77-95.

[28] Yochelson, S. and Samenow, S. (1976): A Study of Thinking Patterns in Criminals. Psych Yogi: a wealth of psychology.

[29] Zweig, M.H. and Campbell, G. (1993). Receiver-operating characteristic (ROC) plots: a fundamental evaluation tool in clinical medicine. Clinical Chemistry, 39, 561-577. 